\title{
GDF-15 in Pulmonary and Critical Care Medicine
}

\author{
Fien M. Verhamme ${ }^{1}$, Christine M. Freeman ${ }^{2,3,4}$, Guy G. Brusselle ${ }^{1,5,6}$, Ken R. Bracke ${ }^{1}$, and Jeffrey L. Curtis ${ }^{2,3,4}$ \\ ${ }^{1}$ Department of Respiratory Medicine, Laboratory for Translational Research in Obstructive Pulmonary Diseases, Ghent University \\ Hospital, Ghent, Belgium; ' ${ }^{2}$ ivision of Pulmonary and Critical Care Medicine, Department of Internal Medicine, and ${ }^{3}$ Graduate Program in \\ Immunology, University of Michigan Medical School, Ann Arbor, Michigan; ${ }^{4}$ VA Ann Arbor Healthcare System, Ann Arbor, Michigan; \\ and ${ }^{5}$ Department of Epidemiology and ${ }^{6}$ Department of Respiratory Medicine, Erasmus Medical Center Rotterdam, Rotterdam, the \\ Netherlands
}

ORCID IDs: 0000-0003-3548-8133 (C.M.F.); 0000-0001-5191-4847 (J.L.C.).

\begin{abstract}
GDF-15 (growth differentiation factor 15) acts both as a stressinduced cytokine with diverse actions at different body sites and as a cell-autonomous regulator linked to cellular senescence and apoptosis. For multiple reasons, this divergent transforming growth factor- $\beta$ molecular superfamily member should be better known to pulmonary researchers and clinicians. In ambulatory individuals, GDF-15 concentrations in peripheral blood are an established predictive biomarker of all-cause mortality and of adverse cardiovascular events. Concentrations upon admission of critically ill patients (without or with sepsis) correlate with organ dysfunction and independently predict short- and long-term mortality risk. GDF-15 is a major downstream mediator of p53 activation, but it can also be induced independently of $\mathrm{p} 53$, notably by nonsteroidal antiinflammatory agents. GDF-15 blood concentrations are markedly elevated in adults and children with pulmonary
\end{abstract}

hypertension. Concentrations are also increased in chronic obstructive pulmonary disease, in which they contribute to mucus hypersecretion, airway epithelial cell senescence, and impaired antiviral defenses, which together with murine data support a role for GDF-15 in chronic obstructive pulmonary disease pathogenesis and progression. This review summarizes biological and clinical data on GDF-15 relevant to pulmonary and critical care medicine. We highlight the recent discovery of a central nervous system receptor for GDF-15, GFRAL (glial cell line-derived neurotrophic factor family receptor- $\alpha$-like), an important advance with potential for novel treatments for obesity and cachexia. We also describe limitations and controversies in the existing literature, and we delineate research questions that must be addressed to determine whether GDF-15 can be therapeutically manipulated in other clinical settings.

Keywords: pulmonary disease; human; mice; biomarkers/blood; cytokine
Discovered over 20 years ago and linked to such crucial biological processes as cachexia, erythropoiesis, and cell survival, GDF-15 (growth differentiation factor 15) nonetheless remains unknown to most pulmonary clinicians and researchers. This status is undeserved because blood concentrations of GDF-15 provide independent prognostic information of all-cause and disease-specific mortality and are increasingly incorporated into algorithms for cardiovascular (CV) disease management. GDF-15 acts both as a cell-autonomous regulatory molecule linked to senescence and as a pleomorphic cytokine. It serves broad-ranging homeostatic roles to integrate the response to cellular stress, especially within the vascular system. GDF-15 has been the topic of several comprehensive reviews (1-4). Our goal in this translational review is to highlight its relevance to pulmonary and critical care medicine.

\section{Key Aspects of GDF-15 Biology}

\section{Genetics and Regulation of Expression}

GDF-15 is a highly divergent member of the transforming growth factor (TGF)- $\beta$ molecular superfamily. Its remarkably low sequence conservation with other superfamily members (15-29\%) (5) suggests unique biological roles. The GDF-15 gene was independently cloned almost simultaneously by six different research groups. The varied strategies they employed led to multiple names (Table 1) (5-12), an early indication of the many organs and processes impacted by GDF-15. Familiarity with these alternative names is useful because several continue to be used even in recent literature. The gene for human GDF-15 (Gene ID 9518; Online Mendelian Inheritance in Man accession no. 605312) resides on chromosomes 19p12-19p13.1. In

(Received in original form November 17, 2018; accepted in final form January 9, 2019)

Supported by Merit Review Awards 101 CX001553 (C.M.F.) and 101 CX000911 (J.L.C.) from the Clinical Laboratory Research and Development Service, Department of Veterans Affairs, and by grant U01 HL137880 (C.M.F. and J.L.C.) from the National Heart, Lung, and Blood Institute, National Institutes of Health.

Correspondence and requests for reprints should be addressed to Jeffrey L. Curtis, M.D., Pulmonary and Critical Care Medicine Section (506/111G), VA Ann Arbor Healthcare System, 2215 Fuller Road, Ann Arbor, Ml 48105-2303. E-mail: jlcurtis@umich.edu.

Am J Respir Cell Mol Biol Vol 60, Iss 6, pp 621-628, Jun 2019

Copyright (C) 2019 by the American Thoracic Society

Originally Published in Press as DOI: 10.1165/rcmb.2018-0379TR on January 11, 2019

Internet address: www.atsjournals.org 


\begin{tabular}{|c|c|c|c|}
\hline Abbreviation & Name & Action Leading to Identification & References \\
\hline GDF-15 & Growth differentiation factor 15 & $\begin{array}{l}\text { Cloning of novel TGF- } \beta \text { family members from a } \\
\text { human placental CDNA library }\end{array}$ & $(6,7)$ \\
\hline NAG-1 & Nonsteroidal antiinflammatory drug-activated gene & Regulation by cyclooxygenase inhibitors & (8) \\
\hline MIC-1 & Macrophage inhibitory cytokine-1 & Upregulation in stimulated macrophages & $(5,9)$ \\
\hline PDF & Prostate-derived factor & Homology to bone morphogenetic proteins & (10) \\
\hline PLAB & Placental bone morphogenetic protein & Inhibition of hematopoietic progenitor proliferation & (11) \\
\hline PTGFB & Placental transforming growth factor- $\beta$ & High expression in placenta & (12) \\
\hline
\end{tabular}

Definition of abbreviation: TGF- $\beta=$ transforming growth factor $-\beta$.

genome-wide association studies, polymorphisms mapping to this region contribute significantly $(27.4 \%)$ to variation in circulating GDF-15 concentrations (13). The human gene comprises two exons of 309 and $891 \mathrm{bp}$, respectively, separated by a single intron of $1,800 \mathrm{bp}$ within the preprodomain of the corresponding peptides $(5,6)$. The 5 '-flanking region of GDF-15 contains one or more binding sites for the transcription factors AP-1 (activator protein 1), AP-2, Nkx-2, p53, Sp1 (specificity protein $1)$, and $\operatorname{Sp} 3(6,8,14,15)$.

In the basal state in humans, GDF-15 transcripts are expressed in virtually all tissues but are highly prevalent in only a few (Table 2). A study that used deep RNA sequencing to examine tissue-specific expression of transcripts in 27 different organs designated GDF-15 as a "mixed high" gene because it was detected at greater than 10 fragments per kilobase of transcript per million mapped reads (FPKM) in all tissues in which it was present (16). Concentrations were highest in placenta, prostate, colon, kidney, and liver, but they were significant ( $>1$ FPKM) in 14 other tissues, including lung. By contrast, concentrations less than 0.5 FPKM were found in lymph node, testis, brain, bone marrow, heart, and skin.

The GDF-15 protein shares properties with other TGF- $\beta$ superfamily members (17). First, it is synthesized as an inactive precursor containing an $\mathrm{N}$-terminal propeptide and a C-terminal mature domain that undergo disulfide-linked dimerization in the endoplasmic reticulum. The propeptide is essential to monitor correct protein folding, the first example of such a quality control function for the propeptide of a secreted protein (18). Second, like TGF- $\beta$, GDF-15 requires proteolytic processing, although unlike TGF- $\beta$, that process occurs in the Golgi apparatus, where the dimeric precursor is cleaved at a conserved RXXR site by a furin-like protease, releasing the bioactive $25 \mathrm{kD}$ disulfide-linked dimer $(5,12,18)$. Matrix metalloproteinase (MMP)-26 (also known as matrilysin 2), but not the structurally similar molecule MMP-7, mediates GDF-15 cleavage in placental trophoblast cells (19). How this intracellular processing step occurs in other cell types is unreported. The U937 macrophage cell line releases unprocessed propeptide, which, by binding to extracellular matrix, might provide latent GDF-15 stores that could contribute to circulating concentrations of mature GDF-15 if subsequently processed extracellularly (20). Third, sequence alignment demonstrates that the C-terminal domain of GDF-15 contains a "cysteine knot," a structural hallmark of the TGF- $\beta$ superfamily produced by its eight intrachain disulfide bonds. However, X-ray diffraction data recently revealed a disulfide bonding configuration $(1 \rightarrow 2,3 \rightarrow 7)$ in GDF-15 not previously observed in TGF- $\beta$ family members (21), another mark of its divergence.

Importantly, GDF-15 can be induced, especially in macrophages; during injury, inflammation, and oxidative stress; and in cancer (2). Known induction stimuli include IL- $1 \beta$, TNF- $\alpha$, macrophage colonystimulating factor, angiotensin II, and TGF- $\beta$. In healthy individuals, GDF-15 concentrations in serum range between 200 and $1,150 \mathrm{pg} / \mathrm{ml}$ (22) and increase with age (23). Aside from pregnancy, where GDF-15 concentrations are high, and reductions predicting miscarriage $(24,25)$, chronic elevations correlate with adverse clinical outcomes. Moreover, GDF-15 is an established or potential biomarker in multiple conditions relevant to pulmonary and critical care medicine.

GDF-15 is strongly induced by p53, a transcription factor that regulates cell cycle progression and cellular survival. Depending on the cellular context, GDF-15 can mediate either pro- or antiapoptotic functions (15, 26-28). GDF-15 protected pulmonary endothelial and epithelial cell lines against hyperoxia in a p53-dependent fashion (29), but whether it does so in vivo is unstudied. The induction of GDF-15 in human umbilical vein endothelial cells (HUVEC) by high glucose concentrations was also p53 dependent and protective. However, GDF-15 can be induced independently of p53; the best-known example is by nonsteroidal antiinflammatory agents (8). GDF-15 production can also be induced in hepatocytes by the unfolded protein response via direct binding of the transcription factor $\mathrm{C} / \mathrm{EBP}$ (CCAAT/enhancer binding protein) homologous protein to its promoter (30). Studies using gene-targeted mice also showed p53 independence of GDF-15 induction in both neonatal and adult injury models (31).

\section{GDF-15 Effects, Receptors, and Signaling}

The effects of GDF-15, both homeostatic and detrimental, involve multiple organ systems (Table 2). GDF-15 regulates neutrophil arrest and platelet aggregation under flow conditions by modulating the affinity of integrins $\left(\beta_{1}, \beta_{2}\right.$, and $\beta_{1}, \beta_{3}$, respectively) (32-34), the first instance of such action by a cytokine. GDF-15 is highly upregulated within atherosclerotic plaques, where it localizes to infiltrating macrophages. GDF-15 also suppresses hepcidin, a master regulator of iron homeostasis, in primary human hepatocytes (a finding not confirmed in mice) $(35,36)$. GDF-15 concentrations are increased in disorders involving ineffective erythropoiesis, and its production by erythroblasts is essential for normal erythrocyte maturation (37). Subcutaneous implantation of GDF-15 in rats induced 
Table 2. Notable Sources and Sites of Action of GDF-15

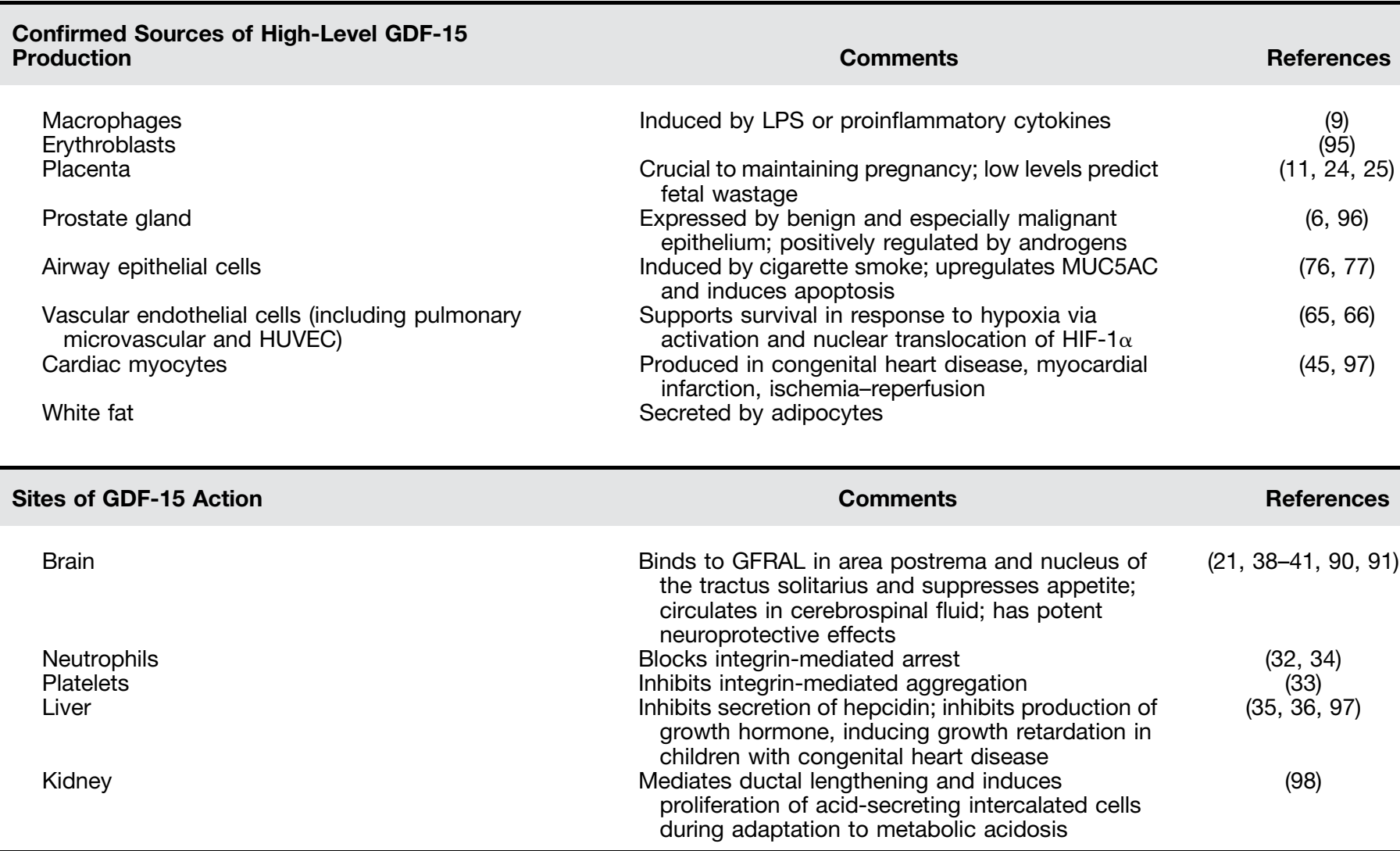

Definition of abbreviations: GDF-15 = growth differentiation factor 15; GFRAL = glial cell line-derived neurotrophic factor family receptor- $\alpha$-like; HIF-1 $\alpha=$ hypoxia-inducible factor $1 \alpha$; HUVEC = human umbilical vein endothelial cells.

cartilage and bone formation (10). This diversity of actions is one reason why a unifying understanding of the regulation and role of GDF-15 remains elusive.

Another significant reason why the knowledge base needed before targeting GDF-15 therapeutically is lacking in most conditions is that the receptors and downstream mediators of its signaling in most tissues have not yet been identified. The sole exception is the newly identified glial cell line-derived neurotrophic factor family receptor- $\alpha$-like (GFRAL) receptor $(21,38-41)$. GFRAL, acting with the receptor tyrosine kinase RET, is a bona fide GDF-15 receptor unrelated to any known TGF- $\beta$ receptors $(21,40)$. GFRAL specifically binds GDF-15, reducing food intake. Via this hormone-like central action, GDF-15 contributes to hyperemesis of pregnancy and to cachexia of malignancy. The converse possibility, that modified forms of GDF-15 or small-molecule agonists of GFRAL could be developed as therapeutic agents to reduce obesity, is discussed below.
Significantly, however, the exclusive expression of GFRAL within the hindbrain confirmed in these studies implies that it does not mediate GDF-15 actions elsewhere in the body.

Considerable research has investigated whether GDF-15 signal transduction mirrors that of other TGF- $\beta$ superfamily members. TGF- $\beta$ ligands generally signal via heterodimer complexes of type I and type II serine/threonine kinase receptors to activate either Smad-dependent (canonical) or Smad-independent (noncanonical) events (21). Several publications have implicated the ALK5 and TGF- $\beta$ type 2 receptors in GDF-15 signaling, whereas the use of the TGF- $\beta$ type 1 receptor remains a subject of debate $(34,39,42-44)$ and might be cell type specific. Although purified GDF-15 did not bind to cell lines transfected with a large number of receptors for TGF- $\beta$ and related molecules $(21,41)$, it remains possible that these systems do not capture the full complexity of ligand-receptor interactions in vivo. Further downstream, involvement of Smad1, but not Smad2, has been demonstrated in cardiomyocytes (21), but non-Smad-mediated signaling of GDF-15 via PI3K, Akt, ERK (extracellular signal-regulated kinase), and mTOR has been reported more frequently $(27,39,40$, $43,44)$. Of these, the PI3K and Akt pathways appear particularly important in GDF-15's antiapoptotic effects after p53 activation $(27,45)$. Importantly, however, the recent observation that TGF- $\beta$ contaminates multiple commercially available sources of GDF-15 (46) mandates circumspection about much of this earlier literature. Hence, elucidating the receptors and signaling pathways by which GDF-15 impacts organs other than the brain is a crucial unmet research goal.

\section{GDF-15 as a Biomarker of Mortality}

Multiple recent studies have confirmed the prognostic value of GDF-15 testing to 
predict all-cause mortality and particularly CV events (47). In patients with heart failure, GDF-15 concentrations are increased relative to those of healthy control subjects $(48,49)$; such elevation has been implicated as causally related to progression (50). In a multicenter study of 646 patients presenting to emergency departments with acute chest pain, GDF-15 concentrations were higher in those with acute myocardial infarction relative to those with other diagnoses, and they predicted 1-year all-cause mortality (51). In a prospective cohort study of 847 patients with acute myocardial infarction, GDF-15 was 1 of 2 biomarkers (of 92) most strongly linked to all-cause mortality (52). That study, the Västmanland Myocardial Infarction Study, followed patients for a median of 7 years and identified GDF-15 and TRAIL-R2 (TNF-related apoptosisinducing ligand receptor 2) as independent predictors of all-cause mortality after adjusting for age, sex, diabetes, previous myocardial infarction, stroke, heart failure, hypertension, smoking, and other factors (52). Similarly, the RE-LY (Randomized Evaluation of Long-Term Anticoagulation Therapy) study measured GDF-15 at randomization of participants $(n=8,474)$ with atrial fibrillation, with a median 2-year follow-up. In models adjusted for other biomarkers, GDF-15 remained significantly associated with all-cause mortality and major bleeding but not with stroke (53). Increased GDF-15 concentrations are also associated with subclinical coronary artery atherosclerosis, assessed by coronary artery calcium score, both in middle-aged adults in the general population (54) and in smokers with chronic obstructive pulmonary disease (COPD) (55). In two different cohorts of patients with peripheral artery disease, the JUVENTAS (Intraarterial Infusion of Autologous Bone Marrow Mononuclear Cells in Patients with Chronic Critical Limb Ischemia) trial $(n=160)$ and the AtheroExpress Biobank Study $(n=386)$, high GDF15 concentrations were associated with an increased risk of major amputation and allcause mortality (56).

GDF-15 also predicts mortality in other conditions. Measurements in critically ill patients (with and without sepsis) upon ICU admission showed a strong association between GDF-15 concentration and organ dysfunction and independently predicted short- and long-term mortality risk (57). Interestingly, in elderly communitydwelling individuals, changes in serum concentrations of GDF-15 over 5 years independently predicted all-cause mortality, which was only partially explained by CV risk factors (58). GDF-15 was recently identified as having the strongest association with chronological aging $\left(P=7.49 \times 10^{-56}\right)$ among 1,301 plasma proteins measured using the SOMAscan assay (SomaLogic) in 240 healthy men and women (59).

Collectively, these findings support the value of GDF-15 concentrations to identify patients at high risk of clinically relevant events or death. No current clinical guidelines have incorporated GDF-15 for this purpose.

\section{GDF-15 in Lung Diseases}

\section{GDF-15 in Pulmonary Vascular Disease}

GDF-15 has been linked to acute and chronic pulmonary vascular diseases, including pulmonary embolism and pulmonary hypertension, in which some of the highest concentrations are observed. Peripheral blood concentrations of GDF-15 at diagnosis of pulmonary embolism predict 30-day outcome risk (60) and mortality (61). GDF-15 is also elevated in adults with pulmonary arterial hypertension (PAH), either idiopathic (62) or systemic sclerosis associated (63), as well as in children with $\mathrm{PAH}$ secondary to congenital heart disease, compared with children with congenital heart disease without PAH (64).

An important research question is whether GDF-15 is not only a biomarker of acute or chronic vascular stress but instead might also contribute to $\mathrm{PAH}$ progression $(63,65)$. GDF-15 production by endothelial cells in vitro is stimulated by shear stress. The cytokine was upregulated in areas of active vascular remodeling in $\mathrm{PAH}$, was expressed by pulmonary vascular endothelial cells, and improved these cells' proliferation and survival in culture (65). Because GDF-15 increased HUVEC proliferation and promoted the formation of functional vessels (44), it is possible that it is elevated in PAH due to pressure overload. An alternative, not mutually exclusive, explanation is that GDF-15 serves a potentially protective role for endothelial cells by promoting the activation and nuclear translocation of HIF-1 $\alpha$ (hypoxia-inducible factor-1 $\alpha$ ), as has been shown in hypoxic human pulmonary microvascular endothelial cells (65) and HUVEC (66). These findings are in apparent disagreement with another study showing that, in HUVEC but not in fibroblasts, GDF-15 blocked the proangiogenic activity of connective tissue growth factor (CCN)-2 to induce vascular tube formation by inhibiting $\alpha_{v} \beta_{3}$-integrin clustering and consequent focal adhesion kinase activation in HUEVC but not in fibroblasts (67). These disparate findings may relate to the different experimental systems examined, but they merit validation in other types of primary human endothelial cells. Importantly, the effect of GDF-15 on endothelial cells in vitro showed dose dependence, stimulating their proliferation at $5 \mathrm{ng} / \mathrm{ml}$ but inhibiting it at $50 \mathrm{ng} / \mathrm{ml}(68)$.

\section{GDF-15 in COPD}

GDF-15 has been examined both as a potential biomarker of COPD severity and prognosis, and as a possible etiologic factor in COPD progression. In stable COPD, circulating GDF-15 concentrations are increased compared with those in healthy control individuals $(49,69)$. Similarly, GDF-15 was increased locally in the airways and lung tissue, at both mRNA and protein concentrations, as well as in quadriceps muscle biopsies of patients with COPD compared with control individuals (69-71). In a cross-sectional analysis of subjects with COPD free of clinical CV disease in the COPDGene cohort $(n=694)$, plasma GDF-15 concentrations correlated independently with subclinical coronary atherosclerosis, as measured by coronary artery calcium scores, whereas no correlation was found with common markers of COPD severity (55). In contrast, high concentrations of GDF-15 upon entry to the Bergen COPD study $(n=413)$ associated with higher annual exacerbation rate, increased mortality, and faster decline in lung function $\left(\mathrm{FEV}_{1}\right.$ and FVC) over 3 years of follow-up (72). This disparity likely relates to the increased statistical power imparted by the longitudinal design of the Bergen COPD study. Elevated GDF-15 has been demonstrated during COPD exacerbations, both in comparison with stable subjects with COPD and control subjects (73), and more tellingly, in paired within-subject comparisons (74). Increased GDF-15 upon hospital admission for COPD exacerbation correlated with adverse outcomes such as the need for endotracheal intubation or inotropic support and 30-day mortality (75). Collectively, these data 
support investigation of GDF-15 as a prognostic biomarker in COPD.

Relative to clinical data, experimental evidence in preclinical models of COPD is less extensive. GDF-15 expression in human small airway epithelial cells was increased by exposure to cigarette smoke extract (71). Using air-liquid interface cultures of human tracheobronchial epithelial cells, Wu and colleagues demonstrated that cigarette smoke exposure upregulated GDF-15 to stimulate MUC5AC expression via the PI3K pathway, but also to induce senescence via the Smad1 pathway $(76,77)$. Recently, the same group showed that GDF-15 overproduction promoted human rhinovirus infection and lung inflammation by inhibiting IFN- $\lambda 1$ (also known as IL-29) (78). We confirmed that exposure to cigarette smoke induces GDF-15 in human airway epithelial cells and in the airways and lungs of a murine model of COPD (70). Collectively, these findings support the potential involvement of GDF-15 in the pathogenesis of COPD progression and exacerbations.

As with other TGF- $\beta$ superfamily members, there is no consensus on whether GDF-15 dampens or aggravates inflammatory processes, as indicated by contradictory results in different disease models, ranging from $\mathrm{CV}$ disease to cancer (1). Our studies show that deletion of the GDF-15 gene in mice leads to reduced lung inflammation after cigarette smoke exposure, suggesting a net harmful effect of the cytokine in this situation (70). Importantly, data from animal models suggest that GDF-15 may also contribute to muscle and adipose tissue wasting in COPD and thus to respiratory cachexia $(69,70)$. Some of this effect appears to result from appetite suppression (79), but GDF-15 also directly induced myotube atrophy in the C2C12 murine myoblast cell line (80).

\section{GDF-15 in Metabolism and Regulation of Body Weight}

\section{GDF-15 concentrations are elevated in} obesity; they decrease after bariatric surgery and are also independently raised in type 2 diabetes (4). GDF-15 has been termed an adipokine because it is secreted by white adipose tissue and has multiple effects that reduce adiposity. Chief among such effects is appetite reduction mediated via GFRAL expression in the hindbrain. The very circumscribed anatomic distribution of
GFRAL could permit highly selective small-molecule agonists to treat obesity or allow inhibitors to correct cachexia in malignancy, heart failure, and advanced COPD, without risking more global effects on the homeostatic roles of GDF- 15 .

However, GDF-15 also alters thermogenesis (81) and increases insulin sensitivity, implying that, like other adipokines such as leptin and adiponectin, it has key systemic actions that regulate body weight and composition. Supporting the potential for these effects to be used to combat the metabolic syndrome, male transgenic mice overexpressing human GDF-15 were resistant to both genetic and diet-induced obesity, showed greater insulin sensitivity and oxidative metabolism, and exhibited lower inflammation than wild-type control animals (81-83). Intriguingly, in contrast to the wealth of data indicating an adverse effect of elevated GDF-15 concentrations (outside of pregnancy) on survival in humans, Kaplan-Meier analysis demonstrated that the median lifespans of female mice from two founder lines overexpressing the human gene were significantly longer than control mice. This difference was greater on a high-fat diet ( $60 \%$ fat vs. $10 \%$ fat) and was associated with decreased signaling through the mTOR pathway, but not with differences in hepatic expression of sirtuin 1 or sirtuin 6 (84). Although it might be tempting to dismiss such improved survival after global overexpression of the human transgene as related to species differences, congruent metabolic effects were observed by a separate group that produced transgenic mice overexpressing the murine gene in a macrophage-specific manner using a modified c-fms promoter sequence $(39,85)$.

Because the native GDF-15 molecule poses challenges to use as a recombinant protein (due to its complex tertiary structure and low circulating half-life), several Fc fusion molecules with extended half-lives and potent efficacy were recently developed. In studies in mice and obese cynomolgus monkeys, these agents delayed gastric emptying, changed food preference, reduced caloric intake, and activated neurons in the area postrema (86). Hence, it is likely that these agents will move toward human testing as a weight reduction therapy, which raises questions about collateral toxicity (based on the senescence-inducing effects of GDF-15) and possible tachyphylaxis of the anorectic effect (given the association of obesity with elevated concentrations of GDF-15, analogous to the situation with the adipokine leptin).

\section{Considerations for Animal Models}

A key research consideration for development of novel therapeutics to target GDF-15 is how faithfully animal data will translate to humans. Most evidence suggests that mouse models will be useful for this purpose. The murine gene for GDF-15 (Gene ID 23886) resides on chromosome 8 in a region showing synteny to the location of the human gene. Indeed, in both species, its nearest protein-encoding neighboring genes-Lrrc25, Pgpep1, and Ssbp4-show similar relationships to GDF-15 in the two species, implying the likelihood of conserved cis-regulatory elements. By compositional matrix adjustment using BLASTP 2.8.1+ $(87,88)$, the molecule displays a high degree of amino acid homology (62\% identity, $76 \%$ positive, $5 \%$ gaps) in the two species. Expression of GDF-15 in various murine tissues in the basal state (89) also parallels that observed in humans (16). These data all support exploiting the convenience and power of transgenic murine models, especially those employing tissue-specific conditional knockouts, to aid in defining the complex biology of GDF-15 expression. In addition to the examples already cited, transgenic mice lacking functional GDF-15 have proven useful in neuropsychiatric research because they exhibit progressive loss of motor neurons and distinctive behavioral patterns (90-92).

One factor potentially complicating translation of murine results to humans is the existence of a microRNA, miR-3189, within the intron of the GDF-15 gene of primates but not of other mammals. In tumor cell lines derived from humans, miR3189 displayed proapoptotic effects that were partially p53 independent, including upregulation of GDF-15 itself (93).

\section{Future Directions (Remaining Research Questions)}

Currently, it is not possible to devise a single unifying explanation for all the varied effects of GDF-15 in health and disease, limiting progress in advancing GDF-15 from a prognostic biomarker to a potential therapeutic target. One reason could be that the binding of GDF-15 to cell surface 
receptors and/or the signaling pathways distal to those receptors might differ between cell types. Confirming the nature and role of GDF-15 receptors in multiple lung parenchymal and inflammatory cell types is a crucial research goal. Future studies should address whether the anorectic effect of GDF-15 accounts entirely for its role in cachexia and examine possible direct contributions to muscle weakness in critical illness (80).

Another unsettled area relates to proteolytic processing of GDF-15. Is MMP-26 the only protease involved in all cell types? Does matrix binding of unprocessed GDF-15 propeptide occur in vivo? If so, does it contribute significantly to local or systemic actions of the cytokine, and how is extracellular processing of GDF-15 propeptide mediated and regulated?

Arguably, the most essential question for development of novel therapies is whether the protective actions of GDF-15 can be dissociated from the generally deleterious effects of sustained high concentrations. Beneficial effects of GDF-15 appear to relate to highly regulated secretion, likely at relatively low concentrations, and as suggested by cell culture experiments, to cellautonomous actions. It will be important for future studies to investigate thoroughly issues of dose and timing. Opposite effects of GDF15 ablation have been observed by different laboratories, not only in the in vitro models cited above but also in murine models of atherosclerosis $(42,94)$, suggesting that chronic therapeutic targeting of GDF-15 may be difficult, aside perhaps from small molecules specifically targeting GFRAL, as discussed above.

\section{Conclusions}

GDF-15 is emerging as a uniquely central homeostatic molecule that, particularly in its role as a circulating cytokine, appears to reflect an integrated attempt by the organism to reduce tissue injury. Whether that attempt ultimately succeeds is highly contextual. Because GDF-15 is well established as an informative prognostic biomarker of mortality and CV outcomes, baseline measurement of GDF-15 should be included in the design of clinical trials in pulmonary and critical care medicine looking at those endpoints. Additional translational studies are warranted to determine whether manipulation of GDF-15 can be beneficial in specific clinical settings.

Author disclosures are available with the text of this article at www.atsjournals.org.

Acknowledgment: The authors thank Bethany B. Moore, Ph.D., and Rachel Zemans, M.D., for reviewing the manuscript and Mohamed R. Kady for performing the BLAST analysis.

\section{References}

1. Breit SN, Johnen H, Cook AD, Tsai VW, Mohammad MG, Kuffner T, et al. The TGF- $\beta$ superfamily cytokine, MIC-1/GDF15: a pleotrophic cytokine with roles in inflammation, cancer and metabolism. Growth Factors 2011;29:187-195.

2. Unsicker K, Spittau B, Krieglstein K. The multiple facets of the TGF- $\beta$ family cytokine growth/differentiation factor-15/macrophage inhibitory cytokine-1. Cytokine Growth Factor Rev 2013;24:373-384.

3. Corre J, Hébraud B, Bourin P. Concise review: growth differentiation factor 15 in pathology: a clinical role? Stem Cells Trans/ Med 2013;2: 946-952.

4. Adela R, Banerjee SK. GDF-15 as a target and biomarker for diabetes and cardiovascular diseases: a translational prospective. J Diabetes Res 2015;2015:490842.

5. Bootcov MR, Bauskin AR, Valenzuela SM, Moore AG, Bansal M, He XY, et al. MIC-1, a novel macrophage inhibitory cytokine, is a divergent member of the TGF-beta superfamily. Proc Natl Acad Sci USA 1997; 94:11514-11519.

6. Böttner M, Laaff M, Schechinger B, Rappold G, Unsicker K, SuterCrazzolara C. Characterization of the rat, mouse, and human genes of growth/differentiation factor-15/macrophage inhibiting cytokine-1 (GDF-15/MIC-1). Gene 1999;237:105-111.

7. Böttner M, Suter-Crazzolara C, Schober A, Unsicker K. Expression of a novel member of the TGF-beta superfamily, growth/differentiation factor-15/macrophage-inhibiting cytokine-1 (GDF-15/MIC-1) in adult rat tissues. Cell Tissue Res 1999;297:103-110.

8. Baek SJ, Kim KS, Nixon JB, Wilson LC, Eling TE. Cyclooxygenase inhibitors regulate the expression of a TGF-beta superfamily member that has proapoptotic and antitumorigenic activities. Mol Pharmacol 2001;59:901-908.

9. Fairlie WD, Moore AG, Bauskin AR, Russell PK, Zhang HP, Breit SN. MIC-1 is a novel TGF-beta superfamily cytokine associated with macrophage activation. $J$ Leukoc Biol 1999;65:2-5.

10. Paralkar VM, Vail AL, Grasser WA, Brown TA, Xu H, Vukicevic S, et al. Cloning and characterization of a novel member of the transforming growth factor-beta/bone morphogenetic protein family. J Biol Chem 1998;273:13760-13767.

11. Hromas R, Hufford M, Sutton J, Xu D, Li Y, Lu L. PLAB, a novel placental bone morphogenetic protein. Biochim Biophys Acta 1997; 1354:40-44.
12. Lawton LN, Bonaldo MF, Jelenc PC, Qiu L, Baumes SA, Marcelino RA, et al. Identification of a novel member of the TGF-beta superfamily highly expressed in human placenta. Gene 1997;203:17-26.

13. Jiang J, Thalamuthu A, Ho JE, Mahajan A, Ek WE, Brown DA, et al. A metaanalysis of genome-wide association studies of growth differentiation factor-15 concentration in blood. Front Genet 2018;9:97.

14. Tan M, Wang Y, Guan K, Sun Y. PTGF-beta, a type beta transforming growth factor (TGF-beta) superfamily member, is a p53 target gene that inhibits tumor cell growth via TGF-beta signaling pathway. Proc Natl Acad Sci USA 2000;97:109-114.

15. Li PX, Wong J, Ayed A, Ngo D, Brade AM, Arrowsmith C, et al. Placental transforming growth factor-beta is a downstream mediator of the growth arrest and apoptotic response of tumor cells to DNA damage and p53 overexpression. J Biol Chem 2000;275:2012720135.

16. Fagerberg L, Hallström BM, Oksvold P, Kampf C, Djureinovic D, Odeberg $\mathrm{J}$, et al. Analysis of the human tissue-specific expression by genome-wide integration of transcriptomics and antibody-based proteomics. Mol Cell Proteomics 2014;13:397-406.

17. Verhamme FM, Bracke KR, Joos GF, Brusselle GG. Transforming growth factor- $\beta$ superfamily in obstructive lung diseases: more suspects than TGF- $\beta$ alone. Am J Respir Cell Mol Biol 2015;52:653-662.

18. Bauskin AR, Zhang HP, Fairlie WD, He XY, Russell PK, Moore AG, et al The propeptide of macrophage inhibitory cytokine (MIC-1), a TGFbeta superfamily member, acts as a quality control determinant for correctly folded MIC-1. EMBO J 2000;19:2212-2220.

19. Li S, Wang Y, Cao B, Wu Y, Ji L, Li YX, et al. Maturation of growth differentiation factor 15 in human placental trophoblast cells depends on the interaction with matrix metalloproteinase-26. $J$ Clin Endocrinol Metab 2014;99:E2277-E2287.

20. Bauskin AR, Jiang L, Luo XW, Wu L, Brown DA, Breit SN. The TGF-beta superfamily cytokine MIC-1/GDF15: secretory mechanisms facilitate creation of latent stromal stores. J Interferon Cytokine Res 2010;30: 389-397.

21. Hsu JY, Crawley S, Chen M, Ayupova DA, Lindhout DA, Higbee J, et al. Non-homeostatic body weight regulation through a brainstemrestricted receptor for GDF15. Nature 2017;550:255-259.

22. Brown DA, Ward RL, Buckhaults $P$, Liu T, Romans KE, Hawkins NJ, et al. MIC-1 serum level and genotype: associations with progress and prognosis of colorectal carcinoma. Clin Cancer Res 2003;9: 2642-2650. 
23. Doerstling S, Hedberg P, Öhrvik J, Leppert J, Henriksen E. Growth differentiation factor 15 in a community-based sample: agedependent reference limits and prognostic impact. Ups $J$ Med Sci 2018;123:86-93.

24. Tong S, Marjono B, Brown DA, Mulvey S, Breit SN, Manuelpillai U, et al. Serum concentrations of macrophage inhibitory cytokine 1 (MIC 1) as a predictor of miscarriage. Lancet 2004;363:129-130.

25. Kaitu'u-Lino TJ, Bambang K, Onwude J, Hiscock R, Konje J, Tong S. Plasma MIC-1 and PAPP-a levels are decreased among women presenting to an early pregnancy assessment unit, have fetal viability confirmed but later miscarry. PLoS One 2013;8:e72437.

26. Heger J, Schiegnitz E, von Waldthausen D, Anwar MM, Piper HM, Euler G. Growth differentiation factor 15 acts anti-apoptotic and pro-hypertrophic in adult cardiomyocytes. J Cell Physiol 2010;224:120-126.

27. Subramaniam S, Strelau J, Unsicker K. Growth differentiation factor-15 prevents low potassium-induced cell death of cerebellar granule neurons by differential regulation of Akt and ERK pathways. J Biol Chem 2003;278:8904-8912.

28. Kim KS, Baek SJ, Flake GP, Loftin CD, Calvo BF, Eling TE. Expression and regulation of nonsteroidal anti-inflammatory drug-activated gene (NAG-1) in human and mouse tissue. Gastroenterology 2002;122: 1388-1398.

29. Tiwari KK, Moorthy B, Lingappan K. Role of GDF15 (growth and differentiation factor 15) in pulmonary oxygen toxicity. Toxicol In Vitro 2015;29:1369-1376.

30. Li D, Zhang H, Zhong Y. Hepatic GDF15 is regulated by CHOP of the unfolded protein response and alleviates NAFLD progression in obese mice. Biochem Biophys Res Commun 2018;498:388-394.

31. Zimmers TA, Jin X, Hsiao EC, McGrath SA, Esquela AF, Koniaris LG. Growth differentiation factor-15/macrophage inhibitory cytokine-1 induction after kidney and lung injury. Shock 2005;23:543-548.

32. Kempf T, Zarbock A, Widera C, Butz S, Stadtmann A, Rossaint J, et al. GDF-15 is an inhibitor of leukocyte integrin activation required for survival after myocardial infarction in mice. Nat Med 2011;17:581-588.

33. Rossaint J, Vestweber D, Zarbock A. GDF-15 prevents platelet integrin activation and thrombus formation. J Thromb Haemost 2013;11: 335-344.

34. Artz A, Butz S, Vestweber D. GDF-15 inhibits integrin activation and mouse neutrophil recruitment through the ALK-5/TGF- $\beta$ RII heterodimer. Blood 2016;128:529-541.

35. Casanovas G, Vujić Spasic M, Casu C, Rivella S, Strelau J, Unsicker K, et al. The murine growth differentiation factor 15 is not essential for systemic iron homeostasis in phlebotomized mice. Haematologica 2013;98:444-447.

36. Tanno T, Bhanu NV, Oneal PA, Goh SH, Staker P, Lee YT, et al. High levels of GDF15 in thalassemia suppress expression of the iron regulatory protein hepcidin. Nat Med 2007;13:1096-1101.

37. Ramirez JM, Schaad O, Durual S, Cossali D, Docquier M, Beris P, et al. Growth differentiation factor 15 production is necessary for normal erythroid differentiation and is increased in refractory anaemia with ring-sideroblasts. Br J Haematol 2009;144:251-262.

38. Emmerson PJ, Wang F, Du Y, Liu Q, Pickard RT, Gonciarz MD, et al. The metabolic effects of GDF15 are mediated by the orphan receptor GFRAL. Nat Med 2017;23:1215-1219.

39. Johnen H, Lin S, Kuffner T, Brown DA, Tsai VW, Bauskin AR, et al. Tumor-induced anorexia and weight loss are mediated by the TGFbeta superfamily cytokine MIC-1. Nat Med 2007;13:1333-1340.

40. Mullican SE, Lin-Schmidt X, Chin CN, Chavez JA, Furman JL, Armstrong AA, et al. GFRAL is the receptor for GDF15 and the ligand promotes weight loss in mice and nonhuman primates. Nat Med 2017;23:1150-1157.

41. Yang L, Chang CC, Sun Z, Madsen D, Zhu H, Padkjær SB, et al. GFRAL is the receptor for GDF15 and is required for the anti-obesity effects of the ligand. Nat Med 2017;23:1158-1166.

42. de Jager SC, Bermúdez B, Bot I, Koenen RR, Bot M, Kavelaars A, et al. Growth differentiation factor 15 deficiency protects against atherosclerosis by attenuating CCR2-mediated macrophage chemotaxis. J Exp Med 2011;208:217-225.

43. Wang CY, Huang AQ, Zhou MH, Mei YA. GDF15 regulates Kv2. 1-mediated outward $\mathrm{K}+$ current through the Akt/mTOR signalling pathway in rat cerebellar granule cells. Biochem J 2014;460:35-47.
44. Wang S, Li M, Zhang W, Hua H, Wang N, Zhao J, et al. Growth differentiation factor 15 promotes blood vessel growth by stimulating cell cycle progression in repair of critical-sized calvarial defect. Sci Rep 2017;7:9027.

45. Kempf T, Eden M, Strelau J, Naguib M, Willenbockel C, Tongers J, et al The transforming growth factor-beta superfamily member growthdifferentiation factor- 15 protects the heart from ischemia/reperfusion injury. Circ Res 2006;98:351-360.

46. Olsen OE, Skjærvik A, Størdal BF, Sundan A, Holien T. TGF- $\beta$ contamination of purified recombinant GDF15. PLoS One 2017;12: e0187349.

47. Wollert KC, Kempf T, Wallentin L. Growth differentiation factor 15 as a biomarker in cardiovascular disease. Clin Chem 2017;63:140-151.

48. Kempf T, von Haehling S, Peter T, Allhoff T, Cicoira M, Doehner W, et al. Prognostic utility of growth differentiation factor-15 in patients with chronic heart failure. J Am Coll Cardiol 2007;50:1054-1060.

49. Mueller T, Leitner I, Egger M, Haltmayer M, Dieplinger B. Association of the biomarkers soluble ST2, galectin-3 and growth-differentiation factor-15 with heart failure and other non-cardiac diseases. Clin Chim Acta 2015;445:155-160.

50. Goletti S, Gruson D. Personalized risk assessment of heart failure patients: more perspectives from transforming growth factor superfamily members. Clin Chim Acta 2015;443:94-99.

51. Schaub N, Reichlin T, Twerenbold R, Reiter M, Steuer S, Bassetti S, et al. Growth differentiation factor-15 in the early diagnosis and risk stratification of patients with acute chest pain. Clin Chem 2012;58: 441-449.

52. Skau E, Henriksen E, Wagner P, Hedberg P, Siegbahn A, Leppert J. GDF-15 and TRAIL-R2 are powerful predictors of long-term mortality in patients with acute myocardial infarction. Eur J Prev Cardiol 2017; 24:1576-1583

53. Hijazi Z, Oldgren J, Andersson U, Connolly SJ, Eikelboom JW, Ezekowitz MD, et al. Growth-differentiation factor 15 and risk of major bleeding in atrial fibrillation: insights from the randomized evaluation of long-term anticoagulation therapy (RE-LY) trial. Am Heart J 2017;190:94-103.

54. Rohatgi A, Patel P, Das SR, Ayers CR, Khera A, Martinez-Rumayor A et al. Association of growth differentiation factor- 15 with coronary atherosclerosis and mortality in a young, multiethnic population: observations from the Dallas Heart Study. Clin Chem 2012;58: 172-182.

55. Martinez CH, Freeman CM, Nelson JD, Murray S, Wang X, Budoff MJ, et al.; COPDGene Investigators. GDF-15 plasma levels in chronic obstructive pulmonary disease are associated with subclinical coronary artery disease. Respir Res 2017;18:42.

56. De Haan JJ, Haitjema S, den Ruijter HM, Pasterkamp G, de Borst GJ, Teraa $\mathrm{M}$, et al. Growth differentiation factor 15 is associated with major amputation and mortality in patients with peripheral artery disease. J Am Heart Assoc 2017;6:e006225.

57. Buendgens L, Yagmur E, Bruensing J, Herbers U, Baeck C, Trautwein $\mathrm{C}$, et al. Growth differentiation factor-15 is a predictor of mortality in critically ill patients with sepsis. Dis Markers 2017;2017:5271203.

58. Eggers KM, Kempf T, Lind L, Sundström J, Wallentin L, Wollert KC et al. Relations of growth-differentiation factor-15 to biomarkers reflecting vascular pathologies in a population-based sample of elderly subjects. Scand J Clin Lab Invest 2012;72:45-51.

59. Tanaka T, Biancotto A, Moaddel R, Moore AZ, Gonzalez-Freire M, Aon $\mathrm{MA}$, et al.; $\mathrm{CHI}$ Consortium. Plasma proteomic signature of age in healthy humans. Aging Cell 2018;17:e12799.

60. Lankeit M, Kempf T, Dellas C, Cuny M, Tapken H, Peter T, et al. Growth differentiation factor-15 for prognostic assessment of patients with acute pulmonary embolism. Am J Respir Crit Care Med 2008;177: 1018-1025.

61. Duran L, Kayhan S, Guzel A, Ince M, Kati C, Akdemir HU, et al. The prognostic values of GDF-15 in comparison with NT-proBNP in patients with normotensive acute pulmonary embolism. Clin Lab 2014;60:1365-1371.

62. Nickel N, Kempf T, Tapken H, Tongers J, Laenger F, Lehmann U, et al. Growth differentiation factor-15 in idiopathic pulmonary arterial hypertension. Am J Respir Crit Care Med 2008;178: 534-541. 
63. Meadows CA, Risbano MG, Zhang L, Geraci MW, Tuder RM, Collier $\mathrm{DH}$, et al. Increased expression of growth differentiation factor-15 in systemic sclerosis-associated pulmonary arterial hypertension. Chest 2011;139:994-1002.

64. Li G, Li Y, Tan XQ, Jia P, Zhao J, Liu D, et al. Plasma growth differentiation factor- 15 is a potential biomarker for pediatric pulmonary arterial hypertension associated with congenital heart disease. Pediatr Cardiol 2017;38:1620-1626.

65. Nickel N, Jonigk D, Kempf T, Bockmeyer CL, Maegel L, Rische J, et al. GDF-15 is abundantly expressed in plexiform lesions in patients with pulmonary arterial hypertension and affects proliferation and apoptosis of pulmonary endothelial cells. Respir Res 2011;12:62.

66. Song H, Yin D, Liu Z. GDF-15 promotes angiogenesis through modulating p53/HIF- $1 \alpha$ signaling pathway in hypoxic human umbilical vein endothelial cells. Mol Biol Rep 2012;39:4017-4022.

67. Whitson RJ, Lucia MS, Lambert JR. Growth differentiation factor-15 (GDF-15) suppresses in vitro angiogenesis through a novel interaction with connective tissue growth factor (CCN2). J Cell Biochem 2013;114:1424-1433.

68. Huh SJ, Chung CY, Sharma A, Robertson GP. Macrophage inhibitory cytokine-1 regulates melanoma vascular development. Am J Pathol 2010;176:2948-2957.

69. Patel MS, Lee J, Baz M, Wells CE, Bloch S, Lewis A, et al. Growth differentiation factor- 15 is associated with muscle mass in chronic obstructive pulmonary disease and promotes muscle wasting in vivo. J Cachexia Sarcopenia Muscle 2016;7:436-448.

70. Verhamme FM, Seys LJM, De Smet EG, Provoost S, Janssens W, Elewaut D, et al. Elevated GDF-15 contributes to pulmonary inflammation upon cigarette smoke exposure. Mucosal Immunol 2017:10:1400-1411.

71. Jiang G, Liu CT, Zhang WD. IL-17A and GDF15 are able to induce epithelial-mesenchymal transition of lung epithelial cells in response to cigarette smoke. Exp Ther Med 2018;16:12-20.

72. Husebø GR, Grønseth R, Lerner L, Gyuris J, Hardie JA, Bakke PS, et al. Growth differentiation factor-15 is a predictor of important disease outcomes in patients with COPD. Eur Respir J 2017;49:1601298.

73. Mutlu LC, Altintas N, Aydin M, Tulubas F, Oran M, Kucukyalin V, et al. Growth differentiation factor-15 is a novel biomarker predicting acute exacerbation of chronic obstructive pulmonary disease. Inflammation 2015;38:1805-1813.

74. Freeman CM, Martinez CH, Todt JC, Martinez FJ, Han MK, Thompson $\mathrm{DL}$, et al. Acute exacerbations of chronic obstructive pulmonary disease are associated with decreased $\mathrm{CD} 4^{+} \& \mathrm{CD} 8^{+} \mathrm{T}$ cells and increased growth \& differentiation factor-15 (GDF-15) in peripheral blood. Respir Res 2015;16:94.

75. Kim M, Cha SI, Choi KJ, Shin KM, Lim JK, Yoo SS, et al. Prognostic value of serum growth differentiation factor- 15 in patients with chronic obstructive pulmonary disease exacerbation. Tuberc Respir Dis (Seoul) 2014;77:243-250.

76. Wu Q, Jiang D, Chu HW. Cigarette smoke induces growth differentiation factor 15 production in human lung epithelial cells: implication in mucin over-expression. Innate Immun 2012;18:617-626.

77. Wu Q, Jiang D, Matsuda JL, Ternyak K, Zhang B, Chu HW. Cigarette smoke induces human airway epithelial senescence via growth differentiation factor 15 production. Am J Respir Cell Mol Biol 2016; 55:429-438.

78. Wu Q, Jiang D, Schaefer NR, Harmacek L, O'Connor BP, Eling TE, et al. Overproduction of growth differentiation factor 15 promotes human rhinovirus infection and virus-induced inflammation in the lung. $\mathrm{Am} \mathrm{J}$ Physiol Lung Cell Mol Physiol 2018;314:L514-L527.

79. Tsai VW, Husaini Y, Manandhar R, Lee-Ng KK, Zhang HP, Harriott K, et al. Anorexia/cachexia of chronic diseases: a role for the TGF- $\beta$ family cytokine MIC-1/GDF15. J Cachexia Sarcopenia Muscle 2012; 3:239-243.

80. Bloch SA, Lee JY, Wort SJ, Polkey MI, Kemp PR, Griffiths MJ. Sustained elevation of circulating growth and differentiation factor15 and a dynamic imbalance in mediators of muscle homeostasis are associated with the development of acute muscle wasting following cardiac surgery. Crit Care Med 2013;41:982-989.
81. Chrysovergis K, Wang X, Kosak J, Lee SH, Kim JS, Foley JF, et al. NAG-1/GDF-15 prevents obesity by increasing thermogenesis, lipolysis and oxidative metabolism. Int J Obes 2014;38:15551564.

82. Kim JM, Kosak JP, Kim JK, Kissling G, Germolec DR, Zeldin DC, et al. NAG-1/GDF15 transgenic mouse has less white adipose tissue and a reduced inflammatory response. Mediators Inflamm 2013;2013: 641851.

83. Wang X, Chrysovergis K, Kosak J, Eling TE. Lower NLRP3 inflammasome activity in NAG-1 transgenic mice is linked to a resistance to obesity and increased insulin sensitivity. Obesity (Silver Spring) 2014;22:1256-1263.

84. Wang X, Chrysovergis K, Kosak J, Kissling G, Streicker M, Moser G, et al. hNAG-1 increases lifespan by regulating energy metabolism and insulin/IGF-1/mTOR signaling. Aging (Albany NY) 2014;6: 690-704.

85. Macia L, Tsai VW, Nguyen AD, Johnen H, Kuffner T, Shi YC, et al. Macrophage inhibitory cytokine 1 (MIC-1/GDF15) decreases food intake, body weight and improves glucose tolerance in mice on normal \& obesogenic diets. PLoS One 2012;7:e34868.

86. Xiong Y, Walker K, Min X, Hale C, Tran T, Komorowski R, et al. Longacting MIC-1/GDF15 molecules to treat obesity: evidence from mice to monkeys. Sci Transl Med 2017;9:eaan8732. [Published erratum appears in Sci Trans/ Med 2018;10:eaav1069.]

87. Altschul SF, Madden TL, Schäffer AA, Zhang J, Zhang Z, Miller W, et al. Gapped BLAST and PSI-BLAST: a new generation of protein database search programs. Nucleic Acids Res 1997;25: 3389-3402.

88. Altschul SF, Wootton JC, Gertz EM, Agarwala R, Morgulis A, Schäffer AA, et al. Protein database searches using compositionally adjusted substitution matrices. FEBS $J$ 2005;272:5101-5109.

89. Yue F, Cheng Y, Breschi A, Vierstra J, Wu W, Ryba T, et al.; Mouse ENCODE Consortium. A comparative encyclopedia of DNA elements in the mouse genome. Nature 2014;515:355-364.

90. Strelau J, Sullivan A, Böttner M, Lingor P, Falkenstein E, SuterCrazzolara C, et al. Growth/differentiation factor-15/macrophage inhibitory cytokine-1 is a novel trophic factor for midbrain dopaminergic neurons in vivo. $J$ Neurosci 2000;20:8597-8603.

91. Machado V, Haas SJ, von Bohlen Und Halbach O, Wree A, Krieglstein $\mathrm{K}$, Unsicker K, et al. Growth/differentiation factor-15 deficiency compromises dopaminergic neuron survival and microglial response in the 6-hydroxydopamine mouse model of Parkinson's disease. Neurobiol Dis 2016;88:1-15.

92. Low JK, Ambikairajah A, Shang K, Brown DA, Tsai VW, Breit SN, et al. First behavioural characterisation of a knockout mouse model for the transforming growth factor (TGF)- $\beta$ superfamily cytokine, MIC-1/GDF15. PLoS One 2017;12:e0168416.

93. Jones MF, Li XL, Subramanian M, Shabalina SA, Hara T, Zhu Y, et al. Growth differentiation factor-15 encodes a novel microRNA 3189 that functions as a potent regulator of cell death. Cell Death Differ 2015;22:1641-1653.

94. Preusch MR, Baeuerle M, Albrecht C, Blessing E, Bischof M, Katus HA, et al. GDF-15 protects from macrophage accumulation in a mousemodel of advanced atherosclerosis. Eur J Med Res 2013;18:19.

95. Forejtnikovà H, Vieillevoye M, Zermati $Y$, Lambert M, Pellegrino RM, Guihard S, et al. Transferrin receptor 2 is a component of the erythropoietin receptor complex and is required for efficient erythropoiesis. Blood 2010;116:5357-5367.

96. Kakehi Y, Segawa T, Wu XX, Kulkarni P, Dhir R, Getzenberg RH. Downregulation of macrophage inhibitory cytokine-1/prostate derived factor in benign prostatic hyperplasia. Prostate 2004;59:351-356.

97. Wang T, Liu J, McDonald C, Lupino K, Zhai X, Wilkins BJ, et al. GDF15 is a heart-derived hormone that regulates body growth. EMBO Mol Med 2017;9:1150-1164.

98. Duong Van Huyen JP, Cheval L, Bloch-Faure M, Belair MF, Heudes D, Bruneval P, et al. GDF15 triggers homeostatic proliferation of acidsecreting collecting duct cells. J Am Soc Nephrol 2008;19:19651974. 